\title{
FACTORIZATION OF FACTORIALS AND A RESULT OF HARDY AND RAMANUJAN
}

\begin{abstract}
MEHDi HASSANi
Abstract. We obtain an explicit approximation for the sum of prime powers in the factorization of $n$ ! into prime numbers. This reproves, as more as gives an explicit version to, a well-known result of Hardy and Ramanujan concerning the summation $\sum_{k \leqslant n} \Omega(k)$.

Mathematics subject classification (2010): 11A41, 11A25, 05A10, 11A51.

Keywords and phrases: Primes, arithmetic functions, factorial function, factorization.
\end{abstract}

\section{REFERENCES}

[1] M. Avalin Charsooghi, Y. Azizi, M. Hassani and L. Mollazadeh-Beidokhti, On a result of Hardy and Ramanujan, Sarajevo J. Math. 4, 17 (2008), 147-153.

[2] S. R. Finch, Mathematical constants, Encyclopedia of Mathematics and its Applications, 94, Cambridge University Press, Cambridge, 2003.

[3] G. HARDY AND S. RAMANUJAn, The normal number of prime factors of a number $n$, Quart. J. Math. 48 (1917), 76-92.

[4] M. HASS ANI, Equations and Inequalities Involving $v_{p}(n !)$, Journal of Inequalities in Pure and Applied Mathematics (JIPAM) 6, 2 (2005), Article 29.

[5] J. BAR KLey RosSER \& L. SCHOENFELD, Approximate Formulas for Some Functions of Prime Numbers, Illinois J. Math. 6 (1962), 64-94. 